\title{
ANALYSIS OF INNER STRUCTURE CHANGES OF CONCRETES EXPOSED TO HIGH TEMPERATURES USING MICRO X-RAY COMPUTED TOMOGRAPHY
}

\author{
Libor SITEK $^{1) *}$, Lenka BODNÁROVÁ ${ }^{2)}$, Kamil SOUČEK ${ }^{1)}$, \\ Lubomír STAS̆ ${ }^{1)}$ and Lucie GURKOVÁ ${ }^{1)}$ \\ 1) Institute of Geonics of the CAS, v. v. i., Studentská 1768, 70800 Ostrava, Czech Republic \\ ${ }^{2)}$ Brno University of Technology, Faculty of Civil Engineering, Veveři 331/95, 60200 Brno, Czech Republic \\ *Corresponding author's e-mail: libor.sitek@ugn.cas.cz
}

\begin{tabular}{l} 
ARTICLE INFO \\
\hline Article history: \\
Received 6 November 2014 \\
Accepted 16 February 2015 \\
Available online 2 March 2015 \\
\hline
\end{tabular}

Keywords:

Concrete

Cement paste

Aggregate

High temperature

\section{ABSTRACT}

The X-ray Computed Tomography (X-ray CT) represents a progressive non-destructive method of analysing the inner structure of materials. The method was used for monitoring changes in inner structure of concrete samples of different composition before and after their exposure to various thermal loads. Eight types of concrete samples were prepared which differed by cement and aggregate types. We intentionally used such composition of concrete mixtures which increased their resistance to high temperatures. The inner structure of samples was analysed using the micro X-ray CT before the thermal loading and after exposure of samples to temperatures of $600{ }^{\circ} \mathrm{C}$ or $900{ }^{\circ} \mathrm{C}$. Damages and character of changes in the inner structure caused by high temperatures were influenced by the character of cement and aggregate we used. The analysis of obtained results is presented in the paper.

\section{INTRODUCTION}

Concrete has many advantageous properties, e.g. inflammability or low temperature conductivity. However, when a concrete construction is exposed to high temperatures, it loses its load-bearing capacity, especially in surface layers which are loaded at most. Serious problem is the so-called explosive spalling which is caused by the combination of increasing pressure in inner pores and inner compressive stresses originating from material expansion at higher temperatures. Spalling of a concrete layer leads to weakening of the concrete cross-section of a reinforced construction and, in some cases, even to the exposure of steel reinforcement to temperatures above the critical level. Defects can be so serious that the complete construction gets destroyed. Design of a concrete mixture with resistance to thermal exposure for a certain period of time has been already classified among the passive fire protection methods. Basic composition of cement concrete can be problematic, as it is a composite material consisting of two markedly different components, i.e. the cement paste and aggregate. When exposed to high temperatures, both components behave differently and their physical, chemical and mechanical properties change.

Experimental research into the aforementioned field of study consists of preparation of test samples according to the preliminary concept of the concrete mixture composition and their testing at high temperatures or during direct flame impingement. The next step is the properties diagnostics of samples which can be based on a wide range of tests and measurements. The only way how to examine changes in the inner structure of concrete after the thermal exposure is to cut a sample and provide consequent macroscopic and microscopic analyses. As it is impossible to evaluate changes in the same sample in unloaded state and in state after the thermal load with traditional methods, we used the micro X-ray Computed Tomography (micro X-ray CT) for the quantitative and qualitative analyses of the inner structure of concrete. The major advantage of this procedure is its non-destructivity during the $3 \mathrm{D}$ visualization and analyses of the studied materials.

\section{USE OF THE X-RAY COMPUTED TOMOGRAPHY IN INDUSTRIAL APPLICATIONS}

Recently, progressive methods for analysing various types of materials have been increasingly applied. One of them is the X-ray Computed Tomography which was originally used for the purposes of medical diagnostics. Based on successful and rapid development of this diagnostic method encouraged by research and development of the X-ray Computed Tomography systems during the 1980s, it begins to be used for industrial applications in materials engineering, including the research into behaviour of biomaterials, as reported by Otani (2004). In this field of research, it is especially advantageous to use the 2D/3D X-ray Computed Tomography systems with high-resolution imaging (the so-called micro X-ray CT) based on the micro focal X-ray source and appropriate line and area (2D) detectors of X-rays which enable to resolve individual picture elements of a $\mathrm{CT}$ slice, or volume elements (voxels), small as units and tens of micrometres in 
size. Although any specific difference between the X-ray CT and micro X-ray CT has not been specified, it can be defined in relation to the space resolution of voxel to the limit value of approximately $200 \mu \mathrm{m}$ which the medical X-ray CT scanners cannot usually reach. The size of a sample examined with the micro X-ray CT method ranges from approximately $40 \mathrm{~cm}$ (large samples) to a few micrometres (small samples). For geosciences and construction materials research, standard samples for the micro X-ray CT are of one millimetre to 5 centimetres in size (Cnudde and Boone, 2013).

The application of the X-ray CT method for quantitative and qualitative analyses of behaviour of different kinds of geomaterials and other related materials, such as rocks, soil, construction materials, ceramic materials and geocomposites (Ščučka and Souček, 2007), is gradually increasing. This nondestructive method for investigations of geomaterials behaviour is also suitable for the 4D visualization and analysis of changes in objects exposed to external factors (for example, stress, thermal exposure, degradation changes of materials, study of liquid-flow in materials, etc. - see Desruess et al., 2006).

\section{ESSENTIALS OF COMPUTED TOMOGRAPHY}

Industrial micro X-ray Computed Tomography utilizes the differences of X-rays properties during the interaction with the mass of a studied material. In case of the X-ray CT, it is especially the ability of X-rays to penetrate various kinds of materials with different levels of their attenuation in relation to properties of analysed objects, especially object density. It is necessary to obtain series of $2 \mathrm{D}$ radiographs for each determined rotation angle during the scanning process of the analysed object with rotation of $360^{\circ}$ for the consequent reconstruction of the $\mathrm{CT}$ volume consisting of individual voxels. The $2 \mathrm{D}$ radiograph projections are realized using the X-rays area detector with the determined number of pixels. The radiograph is a $2 \mathrm{D}$ map of pixels which shows the intensity of attenuation of $\mathrm{X}$ - ray signals passing through the studied object. Different grey levels (grey level scales are determined by the type of detector and its bit scale - 8-bit, 16-bit, etc.) correspond to various intensities of attenuation. Based on sufficient number of projections, the CT volume of the object is reconstructed using algorithm calculations (e.g. the Radon transformation, the inverse Radon transformation or Filtered Back-Projection Method as reported by Kak and Slaney, 1987).

\section{EXPERIMENTAL PROCEDURE}

Preparation of a mixing conception for concretes loaded by high temperatures or fire is not an easily solvable problem. Preparation of our samples was based on our own experiences and recommendations of other authors which have been occupied intensively by the similar problem (e.g. Khoury, 1992; Vydra et al., 2001; Mindeguia et al., 2013; Savva et al., 2005,
Kodur, 2008; Xing at al., 2011 and Scheydt et al., 2012).

\section{AGGREGATE}

When preparing the thermal-resistant concrete mixture, we used the basalt aggregate which shows a long-term resistance to high temperatures due to its character and origin. In addition, we also used the lightweight artificial aggregate from the expanded clay (see European Standards EN 13055-1, EN 14063-1 and EN ISO 9001).

Aggregate from expanded clay has suitable properties in terms of volume stability when exposed to temperatures up to $1050{ }^{\circ} \mathrm{C}$. (Technical guide Liapor). This aggregate is produced in rotary kiln at a temperature of $1100^{\circ} \mathrm{C}$ to $1200^{\circ} \mathrm{C}$. Water absorption of expanded clay aggregate ranges from 2 to $7 \%$ (by weight) after $30 \mathrm{~min}$ and from 7 to $9 \%$ after 24 hours of full immersion in water (Technical guide - Liapor). Behaviour of concrete with this aggregate is significantly affected by the so-called moisture content. The moisture content in concrete is a basic factor which can cause cracks and explosive spalling during the thermal loading (e.g. Kopinga and Pel, 1994). Due to the evaporation of water from expanded clay, pores in concrete are loaded by some additional pressure. If the pressure of vapour is higher than the flexure strength of cement paste, the cement paste breaks and microcracks or explosive spalling are formed (van der Heijden at al., 2007). In terms of fire and heat resistance of lightweight concrete, the two most important factors are the mixing procedure and conditions to which the construction is exposed. The two possibilities of how to dose expanded clay aggregates into concrete mixture are the following:

- in soaked state, with positive effects on workability of concrete and internal curing. Higher moisture content is brought into concrete structure and continuously released during the curing of concrete. The time necessary for water release depends on environmental conditions. This technological process is especially suitable for ready-mix concrete, high performance lightweight concrete and applications in road constructions. Lightweight concrete prepared by this technological process has the moisture content up to $20 \%$ after 28 days of curing;

- in dry state. This technological process is especially used in prefabrication, as the moulding of concrete is fast (within 10 minutes). There is no time for the aggregate to soak up mixing water; however, this procedure reduces the workability of lightweight concrete. Lightweight concrete prepared by this technological process has much lower moisture content (from 3 to $5 \%$ after 28 days of curing).

Concrete test specimens with expanded clay aggregates were prepared according to the first process. The aggregates were stored in water for 
Table 1 Composition of mixtures with basalt aggregate.

\begin{tabular}{lc}
\hline Mixture component & Quantity per m \\
\hline Cement & $350 \mathrm{~kg}$ \\
Water & $175 \mathrm{~kg}$ \\
Aggregate $0-4 \mathrm{~mm}$ basalt & $1070 \mathrm{~kg}$ \\
Aggregate 4-8 mm basalt & $1050 \mathrm{~kg}$ \\
Superplastifier Mapefluid N200 & $6.3 \mathrm{~kg}$ \\
\hline
\end{tabular}

Table 2 Composition of mixtures with basalt and expanded clay aggregate.

\begin{tabular}{lc}
\hline Mixture component & Quantity per m \\
\hline Cement & $375 \mathrm{~kg}$ \\
Water & $125 \mathrm{~kg}$ \\
Expanded clay aggregate 0-4/500 & $0.24 \mathrm{~m}^{3}$ \\
Expanded clay aggregate 4-8/600 & $0.4 \mathrm{~m}^{3}$ \\
Aggregate 0-4 mm basalt & $500 \mathrm{~kg}$ \\
Superplastifier Mapefluid N200 & $4.5 \mathrm{~kg}$ \\
\hline
\end{tabular}

Table 3 Types of cement used in mixtures.

\begin{tabular}{ll}
\hline Portland cement & CEM I 42.5 R \\
Portland composite cement with limestone & CEM II/B-M (S-LL) 32.5 R \\
Portland slag cement & CEM II/B-S 32.5 R \\
Blastfurnace cement & CEM III/B 32.5 N-SV \\
\hline
\end{tabular}

48 hours prior to manufacturing; expanded clay aggregates were used in the soaked state. The moisture content of the concrete with expanded clay aggregates was $12 \%$, while the moisture content of the concrete with basalt aggregates only $4 \%$.

\section{CEMENTS}

In terms of various levels of thermal resistance, four types of cements were chosen as binder for cement mixture preparation, i.e. the Portland cement, the Portland composite cement with limestone, the Portland slag cement and, finally, the Blastfurnace cement. The Portland cement is the most commonly used type of cement in concrete mixing. It was the reason why other cements were compared with this type of cement. Even though, due to low resistance to thermal loads, this cement is not generally used for preparation of thermally stable concretes.

Firstly, 8 different concrete mixtures were prepared using various types of cements and aggregates. Four mixtures were composed of the basalt aggregate; they differed by the used cement. In case of other four mixtures, the mixture of the basalt aggregate and the artificial aggregate from the expanded clay was used. The Table 1 and Table 2 show the composition of all tested mixtures. The types of used cement are specified in Table 3.

Secondly, testing beams of dimensions of about $400 \times 100 \times 100 \mathrm{~mm}^{3}$ were prepared from each concrete mixture. From each analysed type of concrete, a number of cylindrical cores, with a diameter of $22 \mathrm{~mm}$ and height of about $40 \mathrm{~mm}$, were drilled.

Then, the configuration of the used X-ray tomograph was optimised to obtain the best possible quality of individual CT slices. According to the size of analysed tested objects, the size of a voxel (the basic composition element of the reconstructed tomography volume) was about $0.025 \mathrm{~mm}$. The inner structure of cylindrical samples was further scanned with the micro X-ray CT. Subsequently, samples were exposed to the thermal stress of $600{ }^{\circ} \mathrm{C}$ or $900{ }^{\circ} \mathrm{C}$. Samples were heated in accordance with the standard temperature curve ISO 834 (see ISO 834-1) and lasted at the determined temperature for the period of 60 minutes. The standard temperature-time curve ISO 834 (also known as the Cellulosic curve or the standard nominal fire curve) represents a burning rate of fully developed fire in a compartment. It shows that temperature increases with time at a constant rate (see Fig. 1). The curve is defined by the following equation:

$$
\Theta_{g}=T_{0}+345 \log (8 \cdot \boldsymbol{t}+1)
$$

where $\Theta_{g}$ is the temperature of gases in compartment fire $\left({ }^{\circ} \mathrm{C}\right), \quad T_{0}$ represents the temperature in compartment fire before fire outbreak $\left({ }^{\circ} \mathrm{C}\right)$ and $t$ is the duration of the fire (min). After heating at the desired temperature, the samples were cooled at the laboratory 


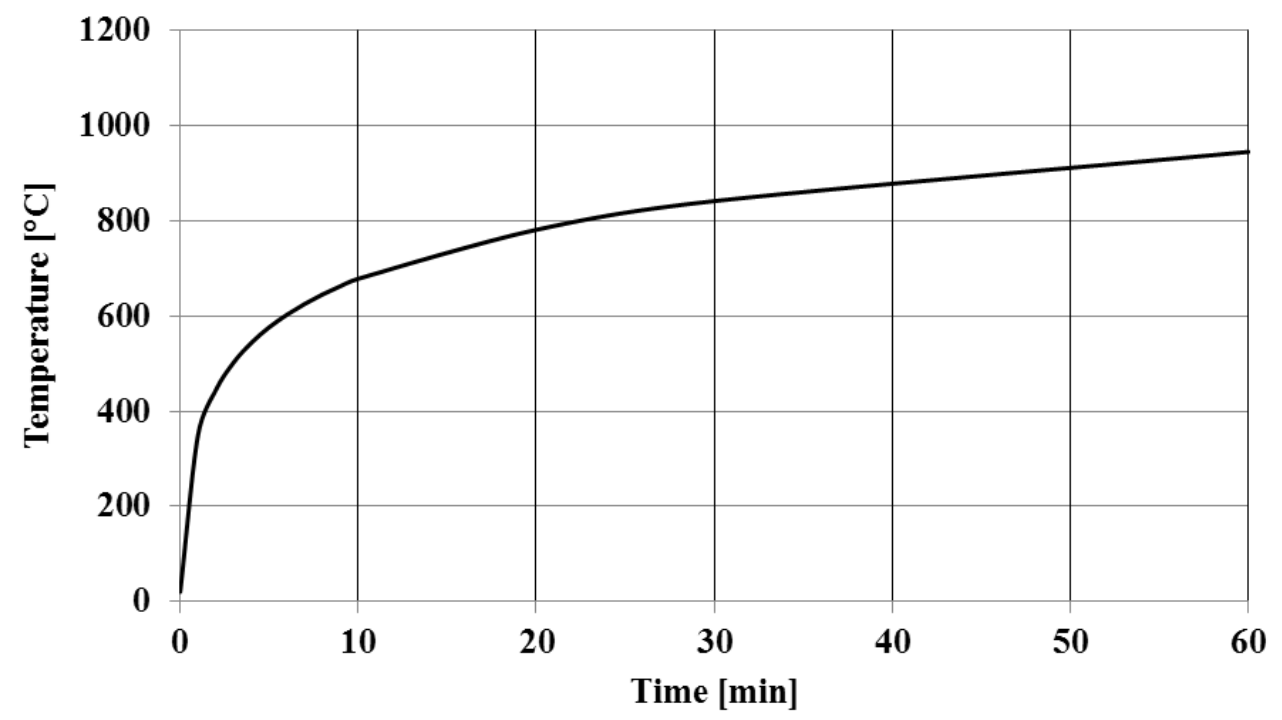

Fig. 1 The standard temperature-time curve ISO 834.

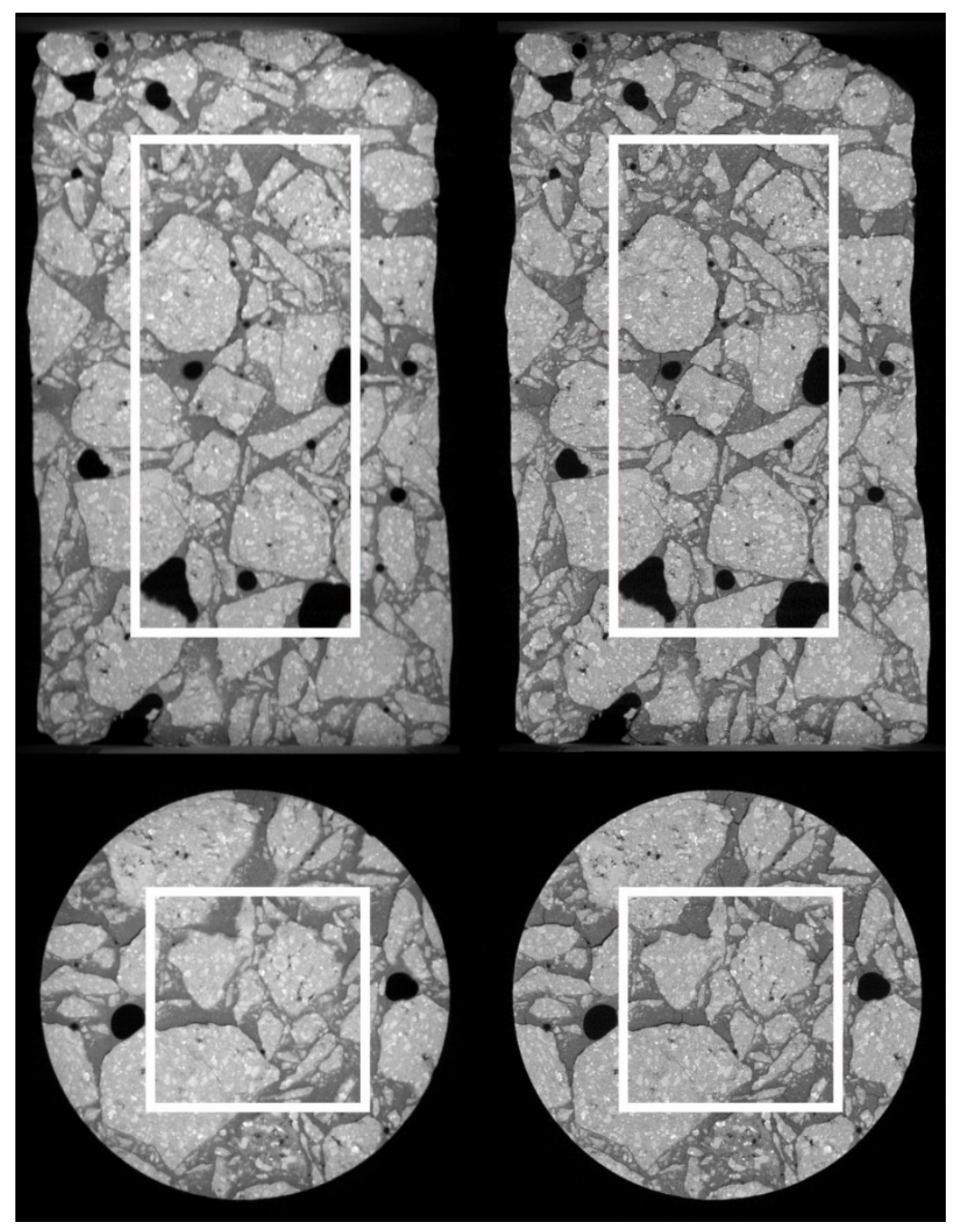

Fig. 2 Definition of the tested space in a concrete sample for detection of the increment in pore space after heating (left - sample before thermal exposure, right - sample after thermal exposure). 

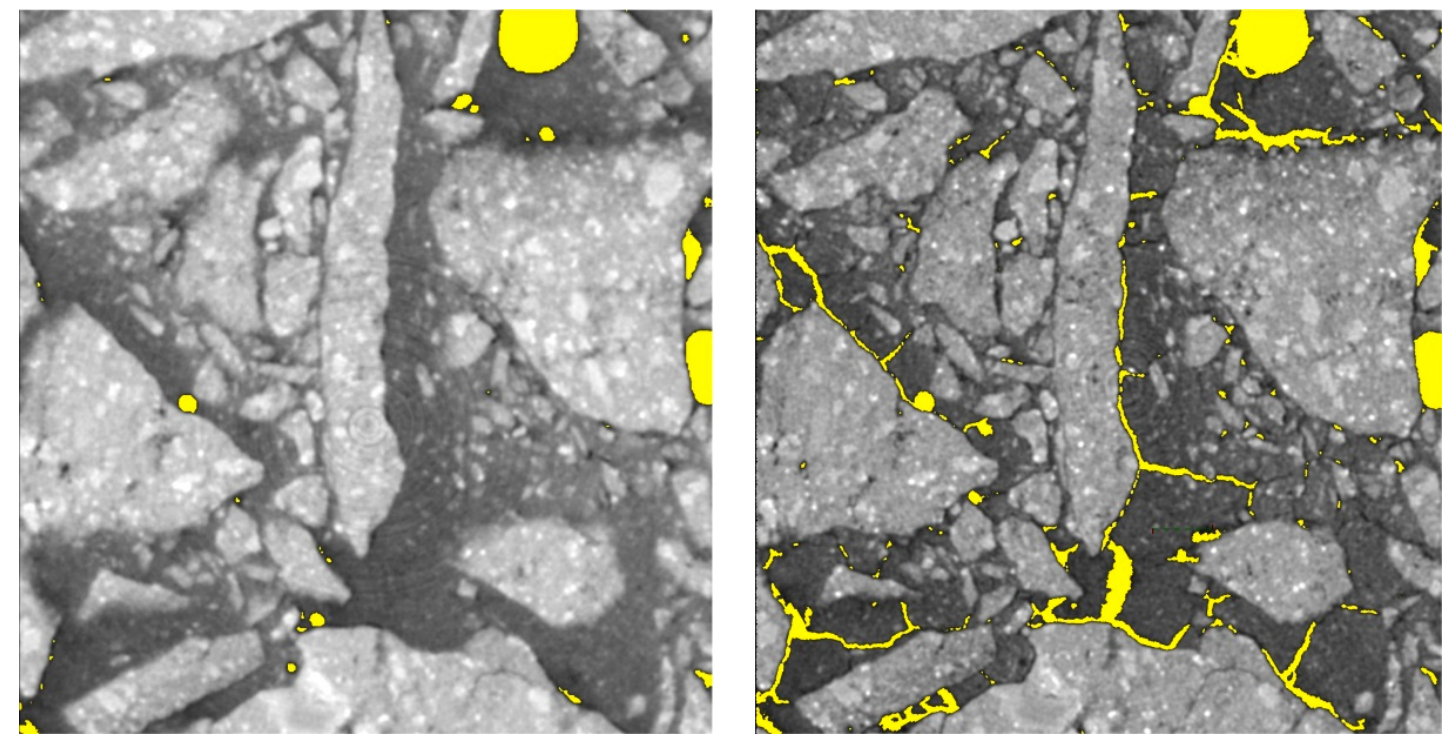

Fig. 3 Example of the analysis of changes in the volume of pore space in one of the CT slices of a concrete test sample before and after the thermal exposure.

Table 4 Specification of XT H 225 industrial micro X-ray CT system used during experiment.

\begin{tabular}{l|l}
\hline $\begin{array}{l}\text { Max. acceleration voltage and power of the X-ray source (reflection } \\
\text { mode) }\end{array}$ & $225 \mathrm{kV} / 225 \mathrm{~W}$ \\
$\begin{array}{l}\text { Max. acceleration voltage and power of the X-ray source (transmission } \\
\text { mode) }\end{array}$ & $180 \mathrm{kV} / 20 \mathrm{~W}$ \\
Size of the X-ray tube focus (reflection mode / transmission mode) & $<3 \mu \mathrm{m} /<1 \mu \mathrm{m}$ \\
Max. weight, diameter and height of scanned objects & $50 \mathrm{~kg} /$ approx. $0.5 \mathrm{~m} / 0.5 \mathrm{~m}$ \\
Max. tomography thickness of analysed materials & $237 \mathrm{~kg} . \mathrm{m}^{-2}$ \\
Sensor of the X-ray radiation (16-bit depth) - area detector & $200 \mu \mathrm{m}$ per pixel, \\
& No. of pixels - $2000 \times 2000$ \\
\hline
\end{tabular}

temperature of $20^{\circ} \mathrm{C}$. Once individual tested objects were cooled, comparative CT scans of the corresponding concrete samples were performed for the consequent evaluation of effects of the thermal load on their integrity. Using the VGStudio Max software, separate reconstructed CT volumes of analysed samples were visualised. Corresponding CT volumes, scanned before and after the thermal exposure, were dimensionally oriented in a way that the tomographic cross-sections with identical position could be simultaneously compared. On so-positioned and visualised cross-sections, effects of high temperatures were evaluated.

For precise quantitative evaluation of failure rate of tempered concrete mixtures, volume of pores space in identical sample before and after heating at the desired temperature were compared. The volume of pore space of the sample analysed before heating is represented mainly by air bubble pores that arise from the technological processing of concrete mixtures during sample preparation. After heat exposure, the volume of pores space is represented not only by air bubbles, but also by cracks in the cement matrix newly formed due to heating. The difference between these two volumes indicates, in a certain way, the rate of resistance of the analysed concrete mixture against the thermal loading. Based on the analysis of reconstructed volumes, changes in pores space were determined again using the micro X-ray CT. Pores space was analysed in the following steps:

- A tested space of approximately equal volume (about $3300 \mathrm{~mm}^{3}$ ) for the analysis of changes in the volume of pores space on an identical sample before and after heating was defined (see Fig. 2). The tested space was positioned in the middle part of the tested sample to eliminate the influence of external boundary conditions. Results from the sample edge can be influenced by an excessive loss of the aggregate and cement binder caused by heating. Thus, it can negatively affect the value of pore space increment.

- Analysis of the volume of pore space was carried out in the tested space of all test samples by determination of a threshold which enabled the differentiation between the pore space and the 
Table 5 Settings of parameters of micro X-Ray CT.

\begin{tabular}{lc}
\hline & X-ray source settings \\
\hline X-ray penetration $[\mathrm{kV}]$ & 150 \\
X-ray Intensity $[\mu \mathrm{A}]$ & $300-400$ \\
X-ray filter & Aluminium, thickness 2.25mm \\
\hline & Settings of CT scanning \\
\hline No. of projections [--] & $2800-3000$ \\
No. of frames per projection [--] & 8 \\
Projection exposure [ms] & 354 \\
Scanning time [h] & approx. 2.5 \\
\hline & Reconstruction \\
\hline Voxel resolution $[\mu \mathrm{m}]$ & 20 - 30 \\
No. of voxels in CT volume & approx. $1.5 \mathrm{E} 9$ \\
reconstruction time $[\mathrm{min}]$ & approx. 10 \\
voxel bit depth / grey levels & 8 -bit / 255 \\
\hline
\end{tabular}

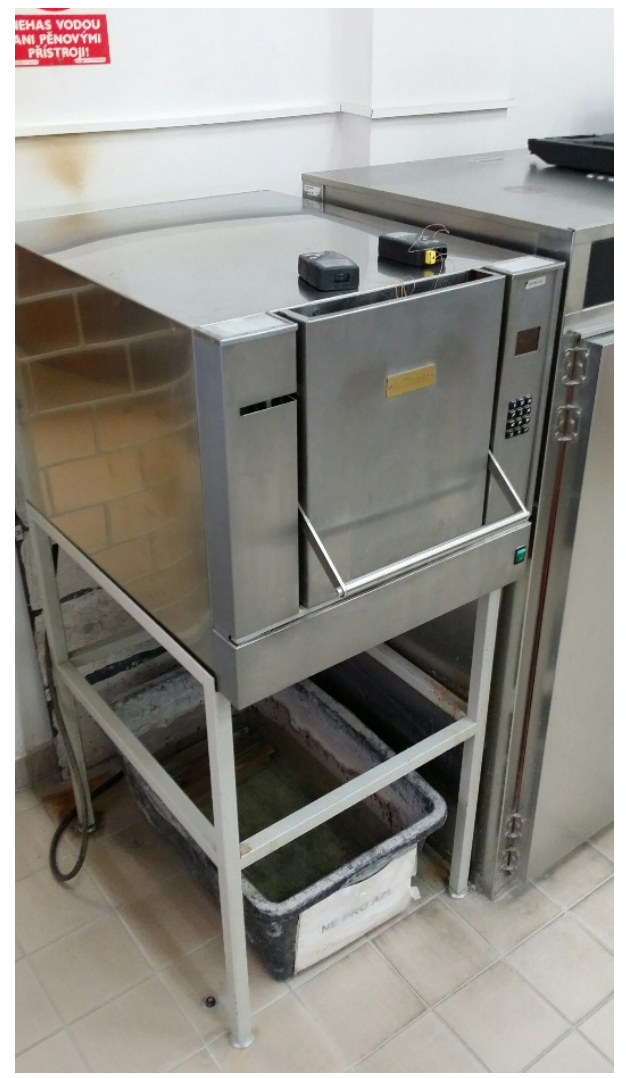

Fig. 4 Testing furnace Classic 1013L and data logger Testo 174-T4 with external temperature probe connections for recording real temperature curve.

rest of concrete material (aggregates and cement binder). Example of the increase in the volume of pore space in one of the test sample sections before and after heating is shown in Figure 3.

- Finally, the increase in the volume of pore space, caused by heating various concrete mixtures up to a temperature of $600{ }^{\circ} \mathrm{C}$ and $900{ }^{\circ} \mathrm{C}$, was calculated and evaluated.

\section{EXPERIMENTAL EQUIPMENT AND CONDITIONS}

For the study of structural changes of concrete test samples exposed to thermal loads, the Nikon Metrology XT H 225 industrial micro X-ray CT system was used. It is a fully automated apparatus with a rotating scanning system equipped with a micro focal X-ray source which generates cone-shaped beams. The used system is specified in Table 4 . Studied volumes were reconstructed using CT Pro 3D and CT Pro 2D software (by Nikon Metrology NV). Visualization was provided by a VGStudio Max software (by Volume Graphics), version 2.2, with additional modules for proper image analysis.

Settings of parameters of the micro X-ray CT system used for scanning the inner structure of concrete materials are presented in detail in Table 5.

Test samples were heated to the desired temperature using an electrically heated laboratory testing furnace Classic 1013L with inner space dimensions of about $800 \times 800 \times 800 \mathrm{~mm}^{3}$. The furnace (Fig. 4) enables to reach and sustain the temperature up to $1100^{\circ} \mathrm{C}$ according to various temperature curves. Current temperature was monitored and recorded using a data logger Testo 174-T4 with external temperature probes connection. Temperature curve for testing followed the standard ISO 834 curve.

\section{ANALYSIS OF RESULTS}

Results of structural changes in test samples after the thermal load are graphically presented as follows. Example of two identical tomographic cross-sections of one sample before and after the exposure to the thermal load of $900{ }^{\circ} \mathrm{C}$ is shown in Figure 5. It demonstrates how easily individual grains of aggregate, air pores, cracks in cement paste, etc. can be identified on a particular CT slice. For an easier comparison of both inner structures, some typical cracks and their average widths are highlighted in structures after thermal exposure. 


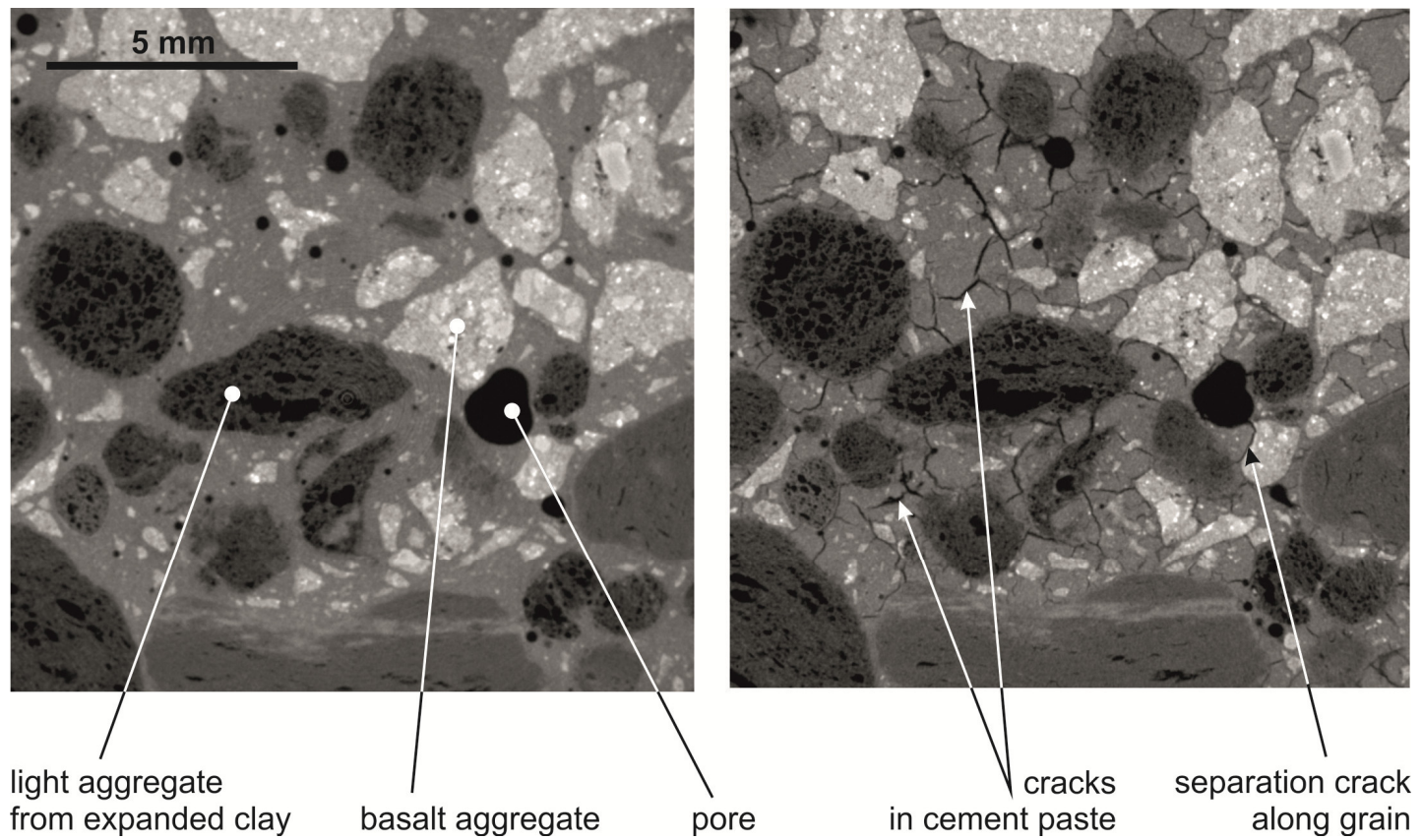

Fig. 5 Changes in the inner concrete structure after the exposure to thermal load (left - structure before thermal exposure, right - the same structure after thermal exposure).
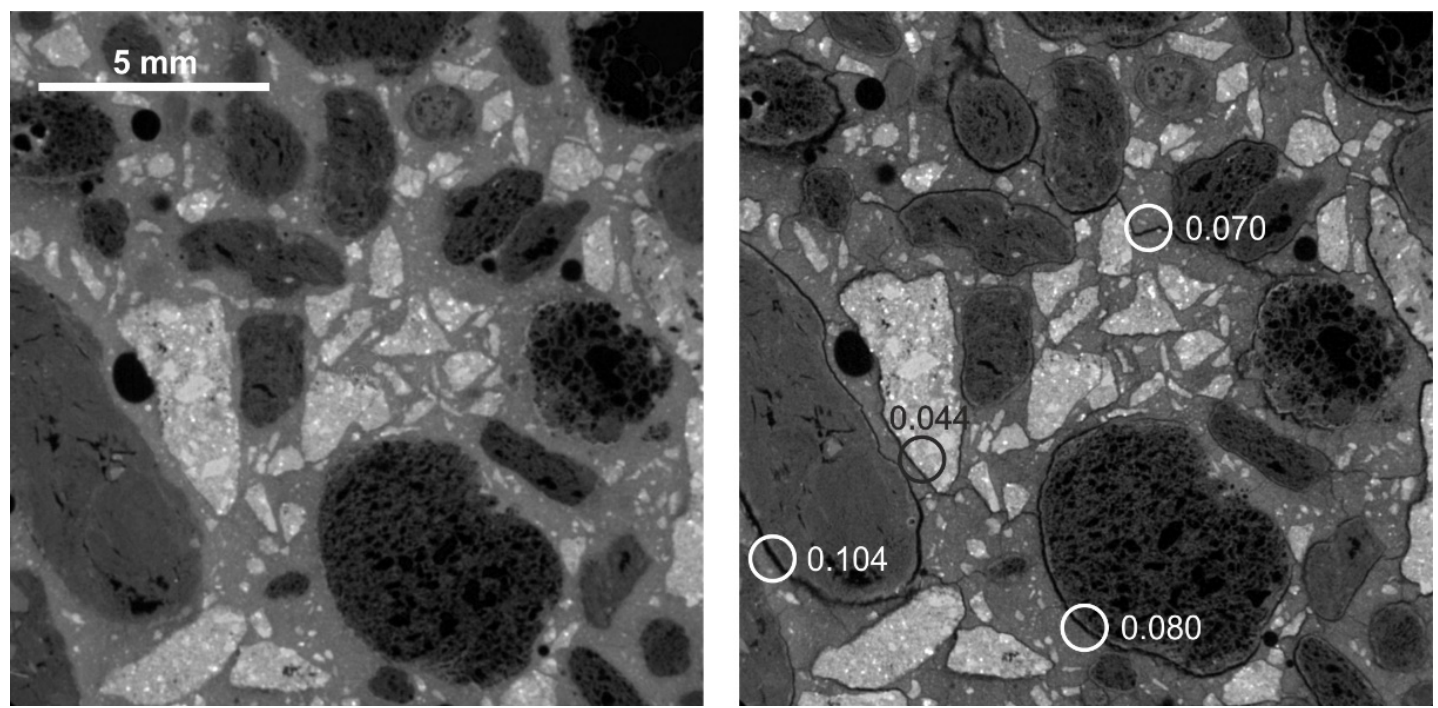

Fig. 6 Concrete with the Portland composite cement, basalt aggregate and lightweight aggregate from expanded clay before and after the exposure to a thermal load of $900^{\circ} \mathrm{C}$ (widths of selected cracks are indicated in millimetres).

It was proved that the type of used aggregate, as well as the type of cement paste, influenced the inner structure of studied samples exposed to a thermal load. Thermally loaded concrete samples with expanded clay were much more damaged (especially by cracks along clay grains) than the concrete samples consisting only of basalt aggregate (compare Fig. 6 and Fig. 7).

Nature of occurred damages were significantly influenced by the type of used cement. It determined whether separation cracks along the aggregate grains (especially along expanded clay - Fig. 6) or cracks in the cement matrix (see Fig. 9) were prevailing in structures of cements exposed to the thermal load. It was generally true that extensive cracks in the cement matrix occurred especially in the matrix consisting of the Blastfurnace cement and the Portland slag cement (for example, Fig. 9). Separation cracks along aggregate grains were more common in the cement matrix prepared from the Portland cement and the Portland composite cement (see Fig. 6 and Fig. 11). The inner structure of the concrete with expanded clay was usually more damaged due to aggregate properties - more water was used in the preparation 

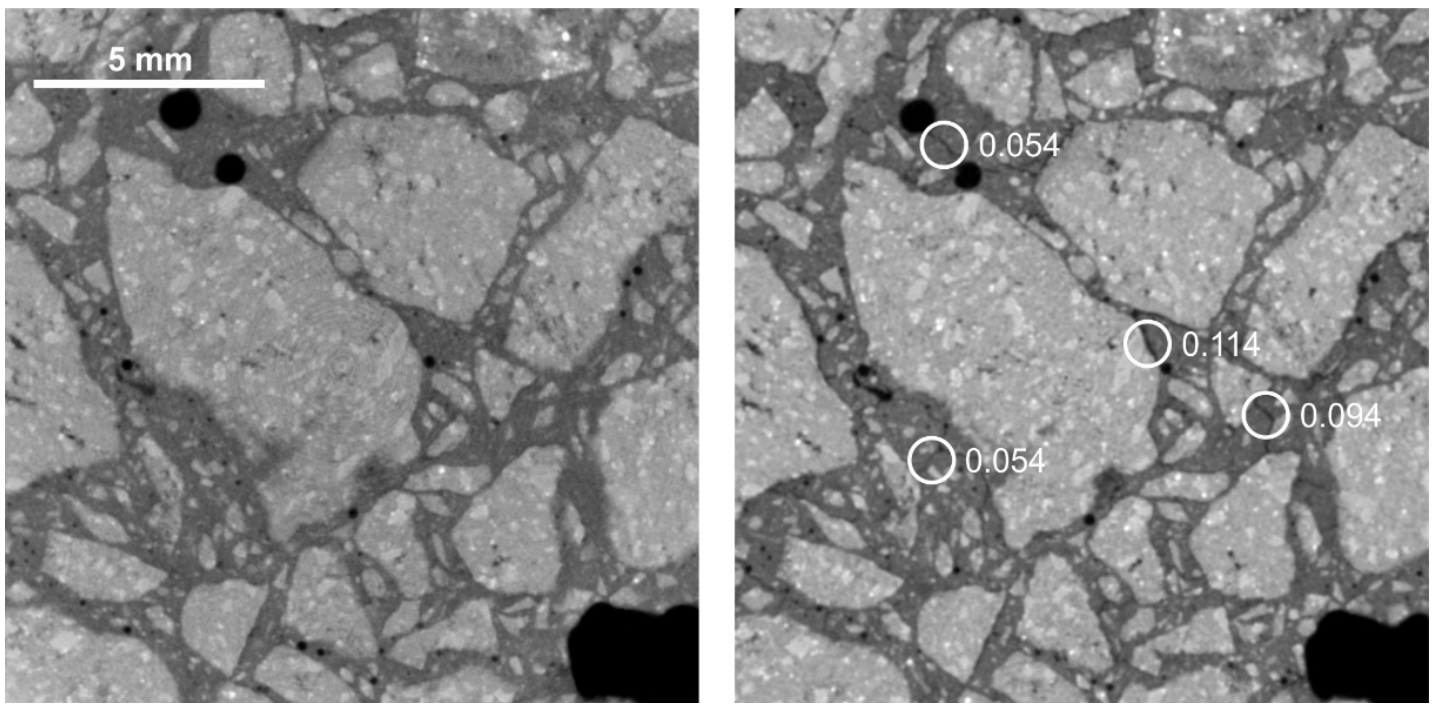

Fig. 7 Concrete with the Portland composite cement and basalt aggregate before and after the exposure to a thermal load of $900^{\circ} \mathrm{C}$ (widths of selected cracks are indicated in millimetres).
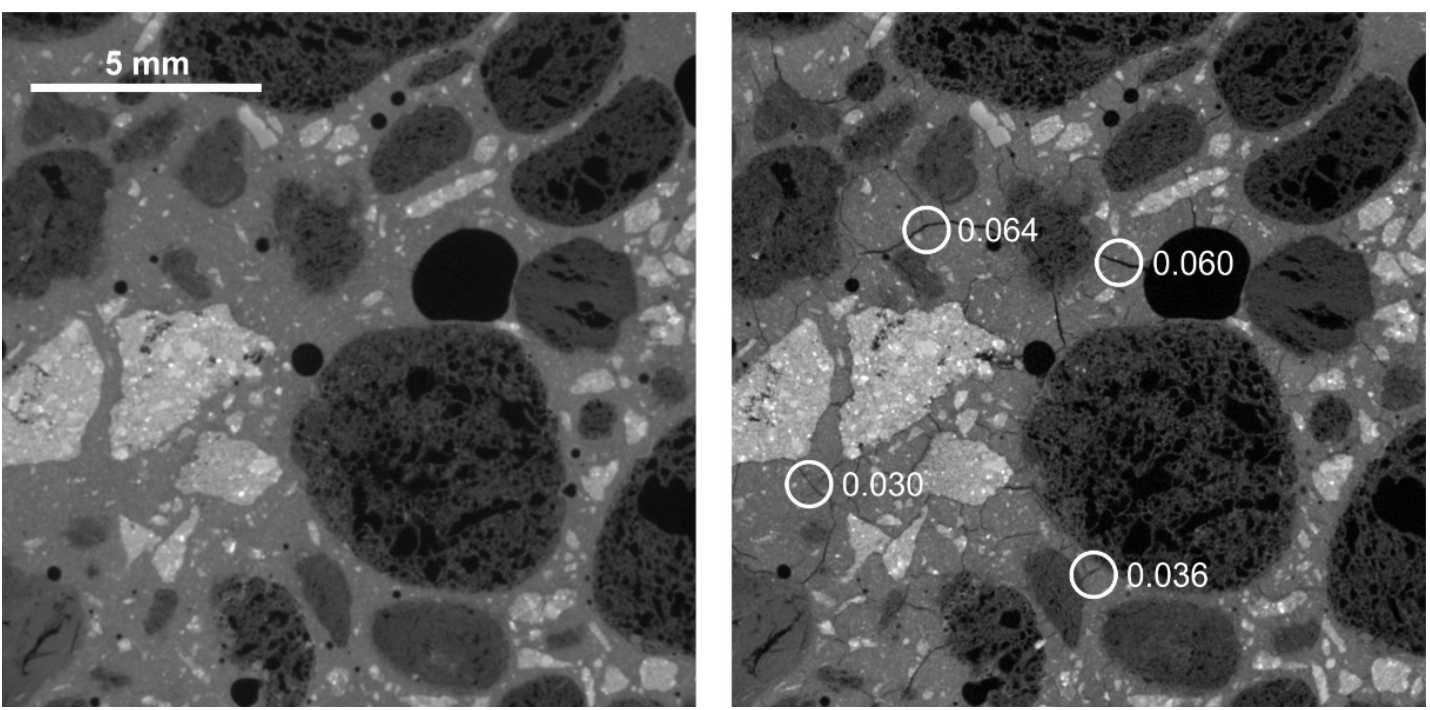

Fig. 8 Concrete with the Blastfurnace cement with basalt aggregate and lightweight aggregate from expanded clay before and after exposure to a thermal load of $600^{\circ} \mathrm{C}$ (widths of selected cracks are indicated in millimetres).
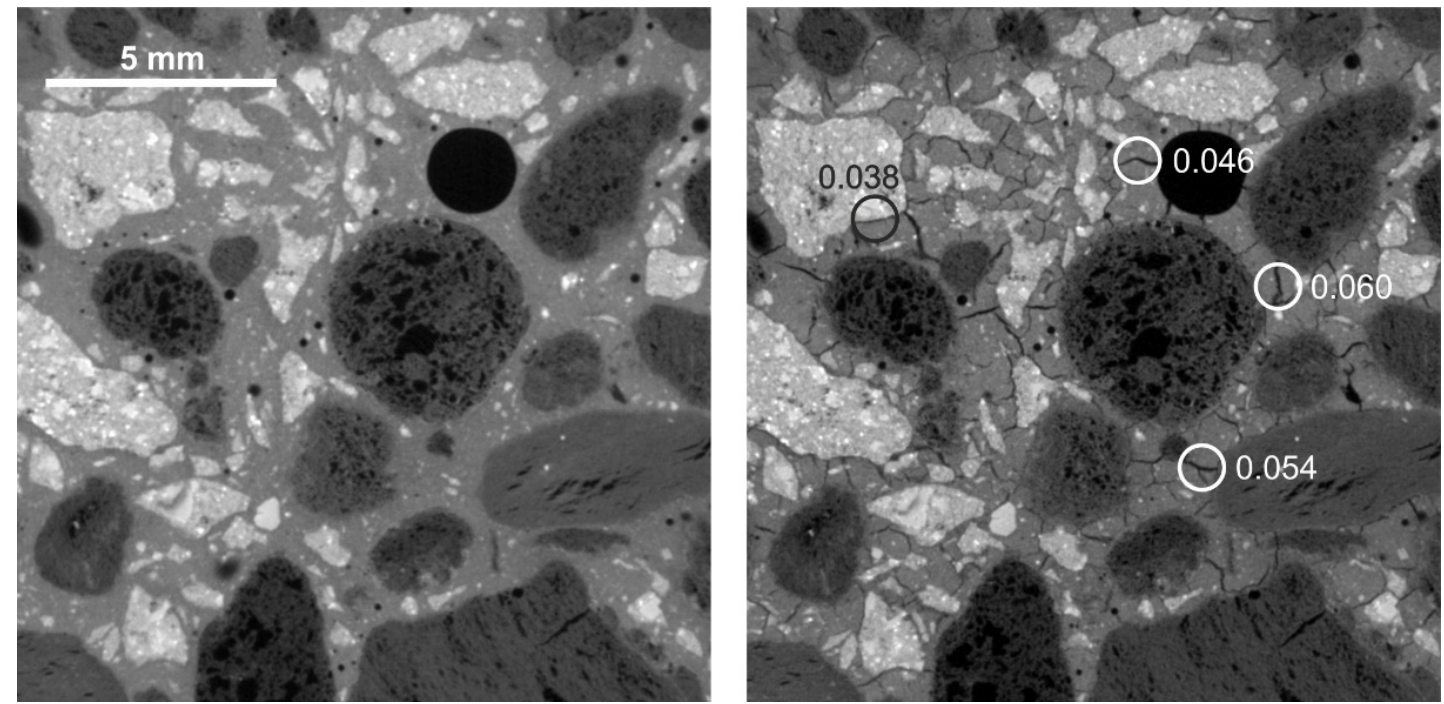

Fig. 9 Concrete with the Blastfurnace cement with basalt aggregate and lightweight aggregate from expanded clay before and after exposure to a thermal load of $900^{\circ} \mathrm{C}$ (widths of selected cracks are indicated in millimetres). 

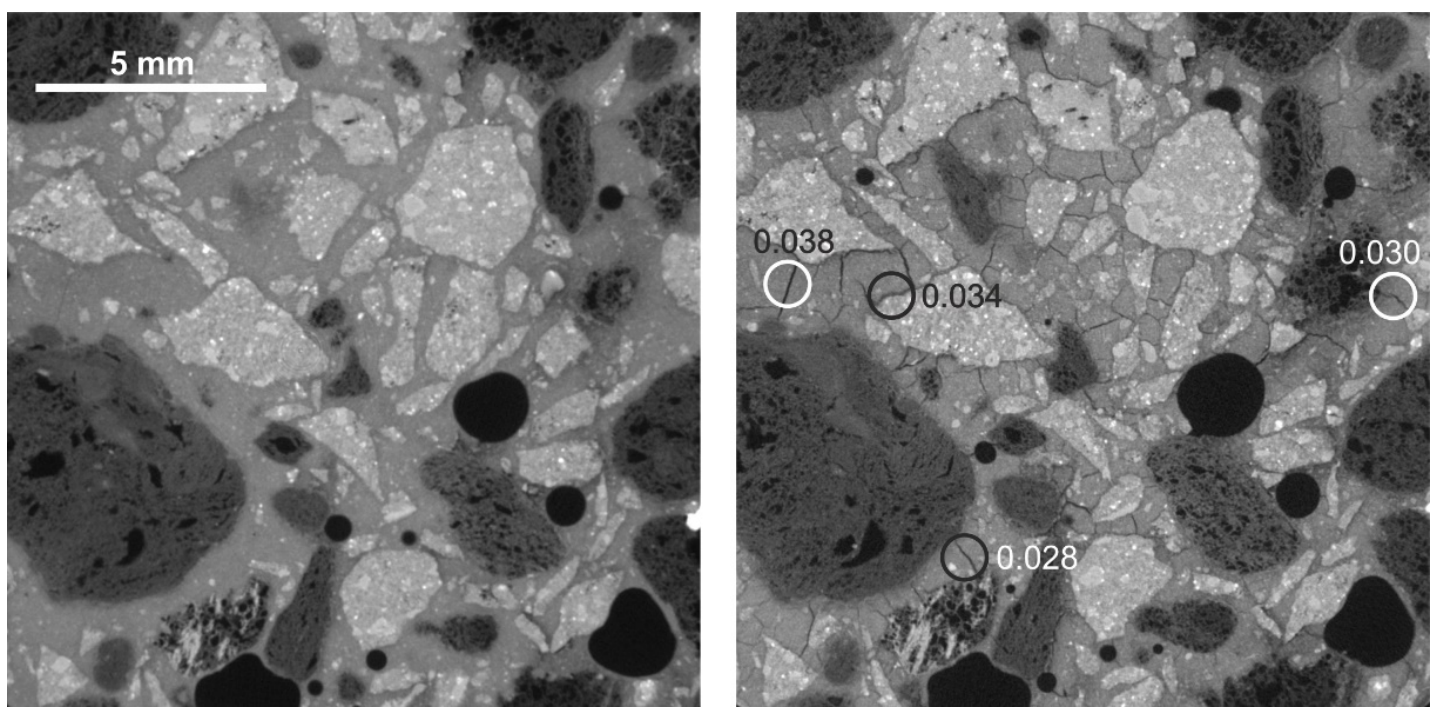

Fig. 10 Concrete with the Portland cement with basalt aggregate and lightweight aggregate from expanded clay before and after exposure to a thermal load of $600^{\circ} \mathrm{C}$ (widths of selected cracks are indicated in millimetres).
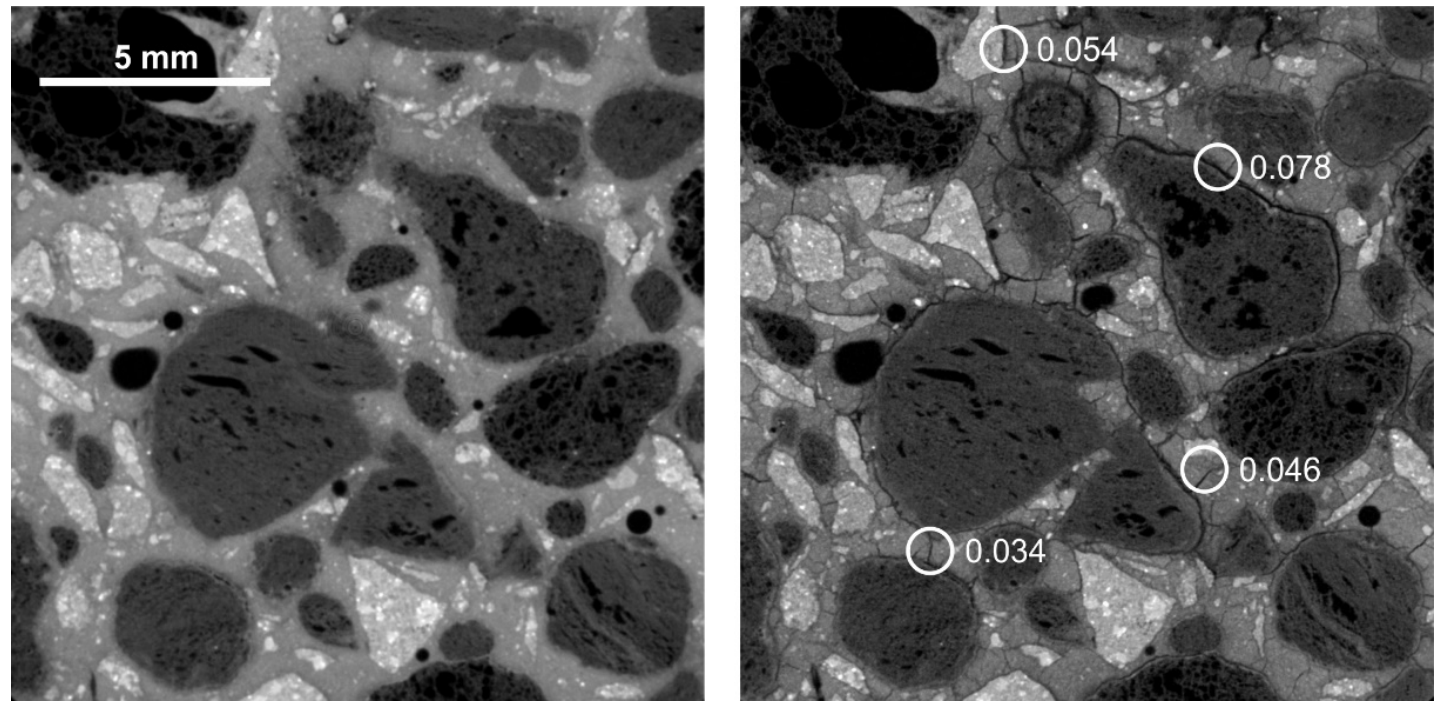

Fig. 11 Concrete with the Portland cement with basalt aggregate and lightweight aggregate from expanded clay before and after exposure to a thermal load of $900^{\circ} \mathrm{C}$ (widths of selected cracks are indicated in millimetres).

process due to the presence of pores in the clay aggregate (see above). Consequently, the cement matrix structure was damaged by the water evaporating from the aggregate.

As expected, the inner concrete structure was more damaged at the higher temperature $\left(900^{\circ} \mathrm{C}\right)$ than at the lower one $\left(600{ }^{\circ} \mathrm{C}\right)$. Cracks occurred in the cement matrix more frequently and they were wider (compare Fig. 8 and Fig. 9). Separation cracks along the expanded clay aggregate only developed when the sample was heated to $900{ }^{\circ} \mathrm{C}$. At a temperature of $600^{\circ} \mathrm{C}$, any of samples did not exhibited cracks along the expanded clay (compare, for instance, Fig. 10 and Fig. 11).
Thermal resistance was visually evaluated (in terms of number, size and character of occurred cracks) on test samples of all tested concrete mixtures heated to $600{ }^{\circ} \mathrm{C}$ and $900{ }^{\circ} \mathrm{C}$. Moreover, the increase in pore space in the tested volume of each sample before and after heating was evaluated quantitatively. This can be interpreted as a formation of new cracks and/or an increase in the volume of existing cracks. This dependence is illustrated in Figure 12. It is obvious that increase in the temperature loading of a sample also leads to a growth of the volume of cracks. Generally, samples with added expanded clay aggregate are more damaged by cracks (expansion of the pore space up to $8 \%$ ), which is apparent from the 


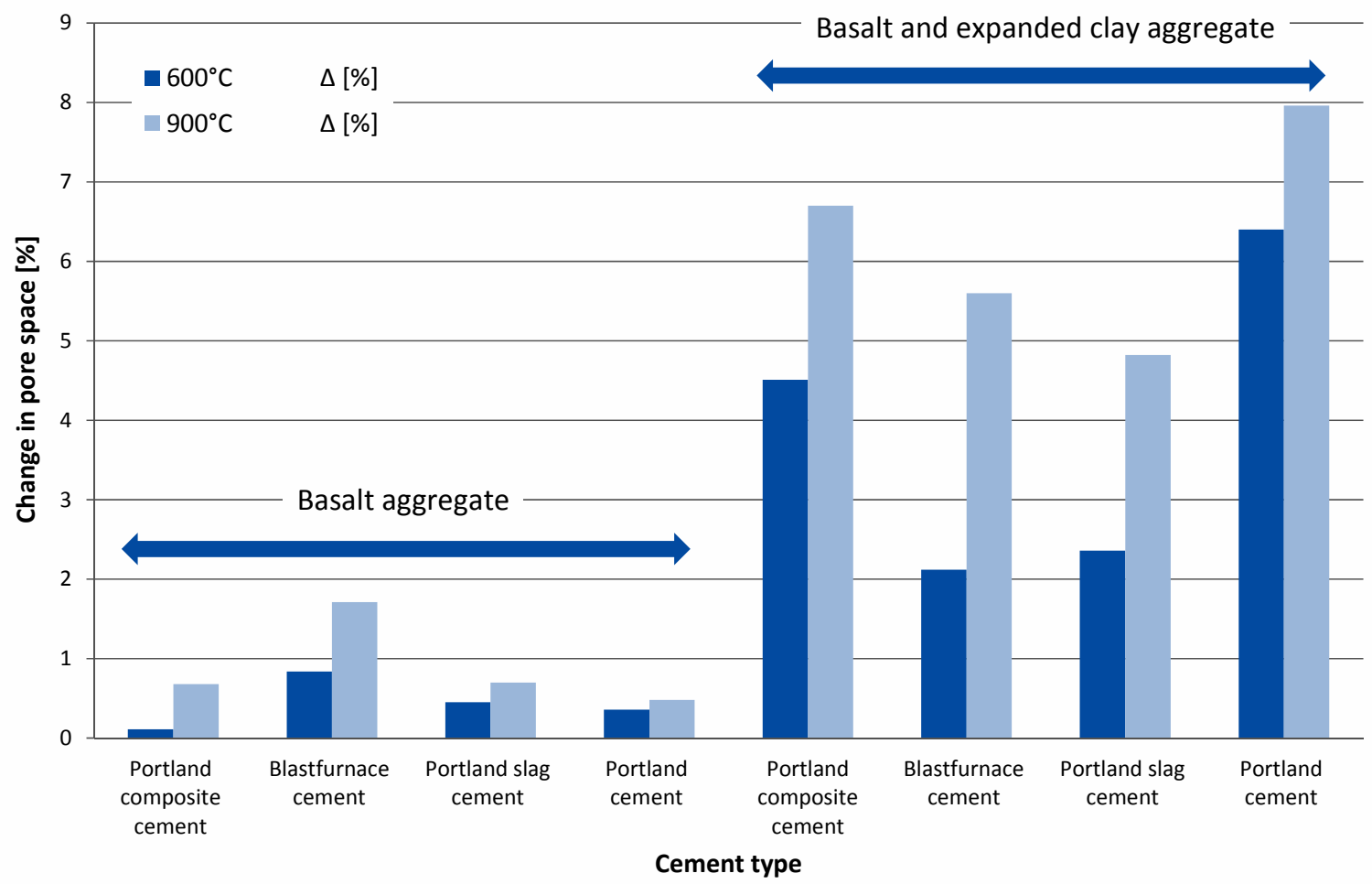

Fig. 12 Change in the pore space in concrete samples with basalt aggregate and basalt + expanded clay aggregate after a thermal loading to $600{ }^{\circ} \mathrm{C}$ and $900{ }^{\circ} \mathrm{C}$.

obtained CT scans. It should mean that the strength of such concretes decreases after a thermal loading. This supposition is supported, for instance, by Kew et al. (2012). They found that the strength of concrete containing higher percentages of lightweight expanded clay aggregates gradually decreased for all tested temperature increments $(100,200,300,400$ and $500{ }^{\circ} \mathrm{C}$ ). In contrast, cracks in samples with basalt aggregate caused the increase in the pore space of the total sample volume only up to $2 \%$ even under a high thermal stress to $900{ }^{\circ} \mathrm{C}$ (Fig. 12).

The matrix made from the Portland composite cement with limestone was the best thermally resistant mixture of all mixtures consisting only of basalt aggregate; the worst results showed the Blastfurnace cement. In contrast, in terms of the mixtures with the expanded clay aggregate and basalt, the best results were achieved with the Blastfurnace cement and the worst results with the Portland cement. The analysis revealed that it is not possible to examine individual concrete components and consequently conclude how the concrete would react as a whole at high temperatures. It is necessary to analyse the whole original structure of the concrete, because thermal expansion and interaction between individual components can lead to surprising results.

\section{CONCLUSION}

The realized research has proved that all components of a concrete mixture, i.e. type of cement and type of aggregate, affect the resistance of concrete to high temperatures. Especially radial cracks in the cement matrix occurred after thermal load in some types of concretes (i.e. concretes with Blastfurnace cement and the Portland slag cement); while separation cracks along the aggregate grains were prevailing by other concretes (i.e. concretes with Portland cement and the Portland composite cement with limestone). The inner structure was more damaged in the samples exposed to higher temperature $\left(900{ }^{\circ} \mathrm{C}\right)$ than to lower one $\left(600{ }^{\circ} \mathrm{C}\right)$. High content of water, occurring in the expanded clay aggregate due to concrete preparation process, caused that the water penetrated the cement matrix at high temperatures. The matrix was then significantly damaged by evaporating water.

When examining the thermal resistance, it is required to study the whole final structure of the concrete, all its components included. In addition, the research shows that the used micro X-ray Computed Tomography can be successfully applied for the analysis of inner damages in concrete samples. It enables to simultaneously compare one and the same sample before and after its exposure to the thermal load without its destruction.

\section{ACKNOWLEDGEMENT}

The presented work was supported by the Grant Agency of the Czech Republic, within the scope of a project of Study of Interactions of Components of 
Cementitious Composites exposed to High Temperatures, No. P104/12/1988, as well as within the scope of a project for the support of long-term strategic development of research organization, RVO: 68145535. The paper was written within the scope of a project of the Institute of Clean Technologies for Mining and Utilization of Raw Materials for Energy Use - Sustainability Program, reg. no. LO1406, which is supported by the Research and Development for Innovations Operational Programme financed by the Structural Funds of the European Union and the State Budget of the Czech Republic, and project No. LO1408 "AdMaS UP Advanced Materials, Structures and Technologies", supported by the Ministry of Education, Youth and Sports under the „National Sustainability Programme I". The authors are very appreciative and thankful for the support.

\section{REFERENCES}

Cnudde, V. and Boone, M.N.: 2013, High-resolution X-ray computed tomography in geosciences: A review of the current technology and applications. Earth-Science Reviews, 123, 1-17. DOI: 10.1016/j.earscirev.2013.04.003

Desruess, J., Viggiani, G. and Bésuelle, P. eds.: 2006, Advances in X-ray Tomography for Geomaterials, ISTE and John Wiley, 2006, London. DOI: $10.1002 / 9780470612187$

EN 13055-1 Lightweight aggregates - Part 1: Lightweight aggregates for concrete, mortar and grout. European Commitee for Standartization. European Standard.

EN 14063-1 Thermal insulation materials and products - In situ formed expanded clay lightweight aggregate products (LWA) - Part 1: Specification for the loosefill products before installation. European Commitee for Standartization. European Standard.

ISO 834-1: 1999, Fire-resistance tests -- Elements of building construction -- Part 1: General requirements. International Organization for Standardization. ISO Standard.

ISO 9001 Quality management systems - Requirements. European Commitee for Standartization. European Standard.

Kak, A.C. and Slaney, M.: 1987, Principles of Computed Tomography Imaging. IEE Press, 49-110.

Kew, H, Donchev, T. and Petkune, N.: 2012, Behaviour of concrete containing lightweight expanded clay aggregates under high temperatures. Proceedings of the 4th International Conference on Concrete Repair, September 26-28, Dresden, Concrete Solutions, 491496.

Khoury, G.A.: 1992, Design of concrete for better performance in fire, in Proceedings of the Institute of Mechanical Engineering Series, Mechanical Engineering Publ., Bury St Edmunds, 121-127.

Kodur, V.: 2008, Designing Concrete Structures for fire Safety. American Concrete Institute.

Kopinga, K. and Pel, L.: 1994, One - dimensional scanning of moisture in porous with NMR. Review of Scientific Instruments, 65, Iss. 12, 3673-3681.

DOI: $10.1063 / 1.1144491$
Mindeguia, J.C., Hager, I., Pimienta, P., Carre, H. and La Borderie, C. 2013. Parametrical study of transient thermal strain of ordinary and high performance concrete. Cement and Concrete Research, 48, 2013, Pages: 40-52. DOI: 10.1016/j.cemconres.2013.02.004

Otani, J.: 2004, State of the art report on geotechnical X-ray $\mathrm{CT}$ research at Kumamoto University in: Otani J., Obara Y. eds., X-Ray CT for Geomaterials: Soils, Concrete, Rocks. International Workshop on X-ray CT for Geomaterials, GEOX2003. AA Balkema, Lisse, 43-77.

Savva, A., Manita, P. and Sideris, K.K.: 2005, Influence of elevated temperatures on the mechanical properties of blended cement concretes prepared with limestone and siliceous aggregates. Cement and Concrete Composites, 27, Iss. 2, 239-248.

DOI: $10.1016 /$ j.cemconcomp.2004.02.013

Scheydt, J.C., Millon, O., Müller, S. and Thoma, K.: 2012, Entwicklung eines brandbeständigen ultrahochfesten Betons für hochdynamische Beanspruchungen. Ernst \& Sohn Verlag für Architektur und technische Wissenschaften GmbH \& Co. KG, Berlin. Beton und Stahlbetonbau, 107, Heft 5. DOI: $10.1002 /$ best.201200009

Ščučka, J. and Souček, K.: 2007, Architecture and Properties of Geocomposite Materials with Polyuretane Binders. Documenta Geonica, Institute of Geonics of the AS CR Ostrava, $247 \mathrm{pp}$.

Technical guide - Liapor, Lias Vintířov, LSM, k.s., 2014 [online]. [cit. 2014-02-11] (accessible from http://www.liapor.cz/administrace/soubory_ke_stazeni $1398154865 \mathrm{cz}$ technicka prirucka zdiva liapor $4 \mathrm{v}$ ydani.pdf).

van der Heijden, G.H.A., van Bijnen, R.M.W., Pel, L. and Huinink, H.P.: 2007, Moisture transport in heated concrete, as studied by NMR, and its consequences for fire spalling. Cement and Concrete Research, 37, iss. 6, 894-901. DOI: 10.1016/j.cemconres.2007.03.004

Vydra, V., Vodák, F., Kapičková, O. and Hošková, Š.: 2001, Effect of temperature on porosity of concrete for nuclear safety structures. Cement and Concrete Research, 31(7), 1023-1026.

DOI: 10.1016/S0008-8846(01)00516-6

Xing, Z., Beaucour, A.-L., Hebert, R., Noumowe, A. and Ledesert, B.: 2011, Influence of the nature of aggregates on the behaviour of concrete subjected to elevated temperature. Cement and concrete research, 41, No. 4, 392-402.

DOI: $10.1016 /$ j.cemconres.2011.01.005 